\title{
PLANTAR, NARRAR E COMER: CONSERVAÇÃO DA ARAUCARIA ANGUSTIFOLIA COMO PROJETO ESCOLAR EM UMA COMUNIDADE RURAL AO SUL DE MINAS GERAIS
}

\author{
Natália Reguera Carvalho iD1, Viviane Santos Pereira iD2, \\ María de Los Angeles Arias Guevara iD3, André Wagner Barata-Silva iD4
}

\section{Resumo:}

Este artigo tem como objetivo refletir sobre experiências ecoformativas e de Educação Ambiental relacionadas à conservação da Araucaria angustifolia, espécie arbórea ameaçada de extinção. As ações empreendidas envolvem uma escola municipal e uma comunidade rural ao Sul de MG. As interações sociais, no processo da observação participante, permitiram extrapolar a sala de aula para abarcar a comunidade como contexto de indagação, diálogo e socialização de aprendizagens. Os conteúdos de Educação Ambiental relacionados à $A$. angustifolia e à cadeia produtiva do pinhão só foram possíveis pela contextualização dos sentidos dos educandos e o estreitamento de laços entre a escola e a comunidade, o qual foi facilitado por docentes propícios ao desenvolvimento e valorização de ações - via atuação do projeto de Educação Ambiental da escola - tais como: resgate do histórico dos projetos, organização e realização de oficina de receitas, participação na oficina sobre preparação de mudas, plantio e confecção livro de receitas com pinhão, entre outras. Ressalta-se, assim, a importância de se trabalhar uma pedagogia que crie condições materiais e psicológicas para que os indivíduos busquem e transformem a relação ser humano-natureza.

Palavras-chave: Ecoformação; Educação Ambiental; Comunidade Rural; Sustentabilidade.

\section{PLANT, NARRATE AND EAT: SCHOOL PROJECT APPROACHING THE CONSERVATION OF ARAUCARIA ANGUSTIFOLIA IN A RURAL COMMUNITY IN SOUTHERN MINAS GERAIS}

\section{Abstract:}

This article aims to reflect on ecoformation and environmental education experiences related to the conservation of Araucaria angustifolia, an endangered Brazilian pine that is an intrinsic part of Campo Redondo community's culture and life. The actions taken involved a municipal school and its local community in the south of MG, which is a Brazilian state. The social interactions in this participant

${ }^{1}$ Graduada em Ciências Biológicas da Universidade Federal de Lavras (UFLA). E-mail: natalia.rcbio@gmail.com

${ }^{2}$ Doutorado em Administração e Professora no Departamento de Administração e Economia da Universidade Federal de Lavras/UFLA. E-mail: vivianepereira@ufla.br

${ }^{3}$ Doutora em Ciências Filosóficas pela Universidade da Habana, Cuba. Professora Estrangeira Visitante no Programa de PósGraduação em Desenvolvimento Sustentável e Extensão (UFLA). E-mail: ariasguevara2011@gmail.com

${ }^{4}$ Doutorando em Fitotecnia na UFLA. Mestre em Desenvolvimento Sustentável e Extensão pela UFLA. E-mail: awbaratasilva@yahoo.com.br

(c) (1) () Py Perspectivas em Diálogo, Naviraí, v. 8, n. 16, p. 328-348, jan./abr. 2021. 
observation process allowed the knowledge building and sense raise that extrapolate the classroom by promoting, along with the community, a context for questioning, dialogue and knowledge sharing. The development of Environmental Education related to $A$. angustifolia and the "pinhão" (it seed) productive chain was only possible due to the student's internalization and sense rise and the closer ties between the school and the community, which was facilitated by teachers who were leading the development and valorization of actions - via performance of the school's environmental education projects - such as: rescue of the project history, organizing and conducting a cooking workshop focused on dishes with "pinhao" that resulted in a collation of recipes for posterior editing and distribution of a booklet to the community, a workshop on seedling preparation and planting, among others, etc. Thus, the importance of working with a pedagogy that creates material and psychological conditions for individuals to seek and transform the human-nature relationship is emphasized.

Keywords: Ecoformation. Environmental Education. Rural community. Sustentability.

\section{Introdução}

O atual estado de fragmentação dos ecossistemas e, como consequência, a extinção de muitas espécies, é resultado da concepção moderna sobre a natureza vista como objeto de apropriação e de mercantilização. Vivemos imersos em um modelo de civilização dominante, que se baseia na superprodução e superconsumo para uns e em subconsumo para a grande maioria, gerando grande desigualdade social e degradação ambiental.

Dessa forma, enfrentamos uma crise ambiental e social complexa e sistêmica, que só pode ser compreendida, quando reconhecemos o conjunto das interrelações e as múltiplas determinações dinâmicas entre os âmbitos ambiental, cultural, histórico, social, econômico e político. Nesse contexto, experiências ecoformativas e de Educação Ambiental surgem como uma ferramenta necessária, propiciando reflexões e ações direcionadas à sustentabilidade.

O uso indiscriminado do conceito de sustentabilidade tem se transformado em um fetiche carente de potencial ético e político. Quase sempre na literatura está relacionado ao de desenvolvimento sustentável, porém é necessário considerar que, no marco desse paradigma, o uso que a racionalidade econômica dominante faz dela tem influenciado a percepção da natureza e as abordagens para conservála. Como mostra Vandana Shiva (1992), a solução que se tem dado à problemática ambiental, resultante do crescimento econômico, faz perder o real significado da sustentabilidade. Para os fins deste trabalho, usamos o conceito desde a perspectiva da ecologia política latinoamericana, que, em uma visão interdisciplinar, confronta o caráter tecnocrático e economicista como o capitalismo verde vê a questão ambiental, ao se tratar de encontrar uma solução à crise enquadrada nos valores neoliberais do mercado. Desse questionamento, emerge a racionalidade ambiental, proposta por Leff (2004), mostrando modos de vida que rearticulam as relações entre a cultura e a natureza. 
Para nossos propósitos, é pertinente a noção sustentabilidade, como poder social proposta por Toledo (2015), desde a perspectiva da ecologia política por sua capacidade regenerativa da estrutura social e restaurativa dos ambientes naturais. Constitui-se, assim, em uma força emancipadora que se inicia em escala microssocial, como famílias e comunidades para logo alcançar outros níveis.

Neste estudo, apresentam-se a temática da Educação Ambiental e as experiências ecoformativas com papel importante, para resgatar a relação sustentável entre as comunidades e a natureza de seu entorno, como inter-relação e interdependência entre sociedade e natureza. O presente trabalho analisa a relação entre a araucária, comunidade e escola rural, no contexto do bioma Mata Atlântica, que, apesar de ser um dos biomas mais ricos em biodiversidade do mundo, é também considerado um dos mais ameaçados do planeta terra. Nesse contexto, o presente estudo se refere à articulação de ações, a partir de uma escola municipal pertencente à comunidade rural de Campo Redondo, situada no município de Itamonte, Sul de Minas Gerais, visando à conservação da espécie arbórea Araucaria angustifolia.

A Araucaria angustifolia é uma espécie florestal, considerada como ameaçada de extinção, encontrada na Floresta Ombrófila Mista, presente no bioma Mata Atlântica. Apresenta uma distribuição geográfica ampla, na região Sul do país e manchas esparsas na região Sudeste, a exemplo do Sul do estado de Minas Gerais (BRASIL, 2008). A semente produzida pela $A$. angustifolia, o chamado pinhão, é considerado como produto da sociobiodiversidade priorizado dentro do contexto da Mata Atlântica, pois, ao mesmo tempo que representa um recurso da biodiversidade, ainda, está conectado a uma identidade cultural e à incorporação de valores e saberes locais, gerando renda, melhoria na qualidade de vida e do ambiente em que vivem as comunidades tradicionais envolvidas diretamente na cadeia produtiva do pinhão (BRASIL, 2009).

Pensar formas, para a conservação e o manejo sustentável da agrobiodiversidade, em que as comunidades, em contato com esses recursos, também são responsáveis pela sua manutenção, pode favorecer a conservação ambiental, trazer melhorias à qualidade de vida e aumento e diversificação à fonte de renda.

$\mathrm{Na}$ comunidade rural de Campo Redondo, a história da relação entre a araucária e o povo abrangeu desde a colonização em que os exuberantes pinheiros, além de sua beleza cênica, promoviam-lhes preciosos bens que, com o passar do tempo, resultou em uma verdadeira e única incorporação cultural, seguido de uma fase econômica em que a araucária foi desmatada de maneira predatória e quase entrou em extinção e, por fim, a proibição do corte da árvore e a volta da "relação sustentável" entre o povo e a araucária pela "cata" do pinhão. Atualmente as florestas de araucárias encontram-se em vulnerável estado de fragmentação, muitos dos remanescentes estão em áreas nas quais há pequenas propriedades rurais. Assim, em razão dessa importância histórica e ambiental, a escola municipal local tem desenvolvido projetos que trabalham a conscientização da relevância da araucária em suas vidas, sua cultura e para o ecossistema.

A ideia de trabalhar com a conservação da araucária foi uma iniciativa da escola municipal e das moradoras da comunidade rural. Uma iniciativa local que desempenha um papel fundamental, educar uma nova geração de moradores que 
saiba valorizar sua fauna, sua cultura e história e, como consequência, cuidar para que essa importante espécie não seja extinta.

As araucárias não apenas formam a beleza da paisagem rural, constituem um elemento central nas tradições alimentares da comunidade. Os ciclos de produção, cata e comercialização do pinhão marcam um cotidiano de lembranças, simbologias, saberes e relações afetivas com a natureza do lugar, mas também resumem as complexas relações que confrontam práticas de conservação com aquelas práticas depredadoras de mercantilização.

O título de trabalho, em sua primeira parte, está inspirado pelos aportes de Brandão (1981), a ideia do lugar, da comida na economia e nas relações entre as pessoas e a natureza, o saber tradicional e todo o mundo simbólico que envolve o cotidiano, mas também a capacidade que tem a comunidade de narrar-se a si mesma, que é aproveitada pela escola nos projetos e ações de Educação Ambiental.

Este artigo tem como objetivo refletir sobre experiências ecoformativas e de Educação Ambiental que envolvem ações relacionadas com a conservação da Araucaria angustifolia na Escola Municipal Bruno Fonseca Pinto, em diálogo com o contexto da comunidade rural do município de Itamonte, situado ao Sul de Minas Gerais. Esta pesquisa é de natureza qualitativa, e foram utilizadas técnicas como observação direta e participante, entrevistas semiestruturadas e análise documental.

O presente trabalho é um dos resultados de um Trabalho de Conclusão de Curso, fruto de uma pesquisa em interface com extensão intitulada "Estudo Sócioambiental com foco na Cadeia Produtiva do Pinhão, a partir de uma visão de Conservação da Araucaria angustifolia, na comunidade rural de Campo RedondoItamonte - Minas Gerais". Buscou-se conhecer o histórico de projetos de Educação Ambiental realizados, além de acompanhar e participar do projeto de educação ambiental desenvolvido pela escola da comunidade, relacionado à conservação da Araucaria angustifolia.

\section{Educação ambiental e ecoformação}

Neste trabalho, assumimos como fundamento a Educação Ambiental crítica, corrente que analisa as dinâmicas sociais que estão nas realidades e problemas ambientais, buscando uma transformação da realidade desde projetos interdisciplinares (SAUVÉ, 2005). A Educação Ambiental crítica permite que os alunos tenham uma visão ampla da realidade, na qual se sintam integrados à sociedade e ao meio ambiente. Seus fundamentos epistêmicos são encontrados nas propostas pedagógicas para uma educação participativa crítico-transformadora discutida por Freire (1983, 1992).

A Educação Ambiental crítica constitui-se em uma sugestão transformadora que extrapola os métodos da ciência tradicional, valorizando a integração entre saberes, construindo a complexidade ambiental (LEFF, 2009), o que é denominado também como "pensamento ecologizante" (MORIN, 2011).

A Educação Ambiental, para Teixeira (2007, p. 25), está relacionada ao conjunto de ensinamentos teóricos e práticos que promovem o entendimento e o despertar da "percepção do indivíduo sobre a importância de ações e atitudes para a preservação e conservação do meio ambiente, tratando-se então de uma 
necessidade atual mediante as práticas e comportamentos predatórios da sociedade moderna". Porém a conscientização, por si só, não mobiliza comunidades rurais a buscarem ações sustentáveis, esse é um esforço que requer a construção de ações integradas.

A Educação Ambiental, segundo Segura (2007), não é uma área de conhecimento isolada, pois surge do contexto de entender a interdependência, pensando em formas de existência mais justas e de equilíbrio, buscando prevenção e solução para problemas socioambientais. Assim, estimula conexões permanentes entre aspectos fundamentais nas relações, tais como ambientais, sociais, econômicos, culturais, político, entre outros.

Numa perspectiva de educação libertadora, como proposto por Freire (1992), entende-se que a Educação Ambiental deve promover espaços de construção de conhecimento com a participação ativa dos sujeitos envolvidos no processo de aprendizagem. Nesse sentido, a Educação Ambiental é trabalhada de forma dialógica e problematizadora, valorizando e incorporando aspectos da comunidade investigada, levando em conta as variáveis inter-relacionadas para buscar ações capazes de transformar determinada realidade.

No contexto escolar, a Educação Ambiental tem o potencial de facilitar aos estudantes uma visão crítica e responsável com reflexos em sua realidade local, formando pessoas que se sintam integradas à natureza e à sociedade (CARVALHO, 2008). Nessa ótica, a ideia de ecoformação pode contribuir com avanços na Educação Ambiental, à medida que possibilita uma visão mais ampliada dos processos formativos (dentro e fora do ambiente escolar), desde que se reconheça a inter-relação dos fenômenos que formam a realidade.

A ecoformação "pressupõe o desenvolvimento de ações educativas ecologizadas, constitutivas de um processo formativo em que se constrói o conhecimento, ao mesmo tempo em que são trabalhadas as diferentes relações do indivíduo consigo mesmo, com o outro e com a natureza" (MORAES, 2019 p. 84). A ecoformação supõe interação e reconstrução de relações entre indivíduo, sociedade e natureza com um profundo valor educativo comprometido com a solidariedade, com toda a Terra e seus habitantes (NAVARRA, 2007).

Para Silva (2008), a ecoformação perpassa pelo cotidiano, uma educação que ocorre, durante a vida e em todos os aspectos da prática humana, mediada pela relação entre os homens, entre homens e ambiente e do homem consigo mesmo. "Constitui uma concepção, ao mesmo tempo, construtivista, interdisciplinar complexa e permanente de educação ambiental" (SILVA, 2008 p. 100).

A aproximação da educação ambiental e ecoformação possibilita integrar e sensibilizar os diversos segmentos da sociedade, para que unam esforços em prol da sustentabilidade, em uma perspectiva mais ampla, bem como pensar e entender os processos formativos em espaços formais e em ambientes informais, no próprio cotidiano da vida (NAVARRA, 2007).

Entendemos que trabalhar desde a perspectiva teórica assumida para a Educação Ambiental requer apropriação no sentido freiriano de conceitos como trabalho, diálogo, libertação que junto à conscientização perpassam sua obra assemelhando-se à ideia de complexidade proposta por Morin. Para Freire (1992), o homem forma a si mesmo, contribui com a formação de outros homens e de seu ambiente. Morin propõe uma trindade humana composta por indivíduo, espécie e 
sociedade, que estão inter-relacionados, sendo a teoria da complexidade, condição teórica metodológica para a compreensão dessa trindade (SILVA, 2008).

Como a conscientização adquire diversas conotações, para os fins do presente estudo, assumimo-la como "...desenvolvimento crítico da tomada de consciência" (FREIRE, 1980, p. 25), propiciado pelo processo educativo. Freire (1980) insiste que a educação deve provocar uma atitude crítica, de reflexão, que comprometa a ação cujo diálogo é sua mediação pedagógica.

\section{Conservação da Araucaria Angustifolia}

A araucária é uma importante fonte de alimento, muito rica em carboidrato, proteína, fibra, cálcio, fósforo, reservas energéticas e vitaminas, sendo útil para a alimentação humana, para animais de criação e silvestres (CERTI, 2012). Também existe potencial para sua utilização na tecnologia dos alimentos e para uso de suas propriedades medicinais. Sendo assim, o pinhão tem ganhado espaço, sendo reconhecida a importância da inserção desse produto em estratégias, para a conservação das florestas nativas, aliado ao desenvolvimento humano dentro do Plano Nacional de Promoção dos Produtos da Sociobiodiversidade/PNBSB.

De maneira geral, o debate sobre a conservação da araucária está mais relacionado ao avanço de conhecimentos técnicos e científicos voltados para o aumento da produção de pinhões (DANNER et al., 2012), à medida que poucos foram os trabalhos em que se discutiu a necessidade de investigar as potencialidades de se trabalhar a conservação da araucária atrelada ao desenvolvimento socioeconômico no campo. Amaral e Fichino (2014) reconhecem a considerável produção técnico-científica com base nas informações sobre a Araucaria angustifolia. No entanto observaram a falta de estudos sistematizados sobre as relações de uso e conservação da espécie, o que remete a uma demanda de estudos conduzidos dentro desta interface.

Dessa forma, observa-se espaço para trabalhos conduzidos, a partir da percepção de comunidades rurais, relacionando ações que poderiam incentivar o plantio de araucária pelos próprios atores que dependem economicamente dessa espécie, valorizando sua cultura e seu produto regional, a fim de beneficiar a realidade local. Assumimos, neste estudo, em comunidades rurais, aqueles agrupamentos humanos que contam com uma história comum, compartilham tradições, valores, práticas sociais e produtivas vinculadas ao setor agropecuário, serviços ou agroindustriais, ajustando-se a indicadores demográficos estabelecidos em cada país.

De acordo com Floriani (2007), as comunidades rurais podem ser um dos principais parceiros para a conservação da floresta de araucárias pelos saberes acumulados e pelo fato de produtores ocuparem uma área significativa composta por remanescentes desse ecossistema em suas unidades produtivas. Mas cabe ressaltar que nem todas as práticas relacionadas ao pinhão ocorrem de forma sustentável por várias questões (sociais, ambientais, econômicas, etc.). Nesse sentido, os esforços para a conservação da Araucaria angustifolia devem envolver as comunidades que dependem de alguma forma do pinhão, como complemento de renda e fonte de alimento, pela relevância cultural para as comunidades rurais. 


\section{Contexto de estudo e metodologia}

O estudo do rural e das comunidades rurais, na teoria sociológica clássica e na sociologia do desenvolvimento, é permeado pelas separações impostas pela modernidade, sendo marcado por conceitos, como sociedade arcaica, sociedade tradicional, vista como uma sociedade de "solidariedade mecânica" em comparação à "solidariedade orgânica" (DURKHEIM, 1987). A "comunidade" é definida por relações de parentesco, de vizinhança, de confiança e solidariedade, como dissera Ferdinantd Tonnies (1947), construindo uma falsa noção de "comunidade rural", como uma organização social homogênea reciprocamente diferenciada de uma "comunidade urbana", cuja totalidade de indivíduos estaria ativamente envolvido em uma atividade agrícola, uma população rural passiva e indiferenciada.

Autores como Wirth (1973), Fichter (1973), MacIver e Page (1973) enfatizam sua base territorial e as relações existentes entre coesão social e área geográfica como elemento fundamental para a compreensão de uma comunidade. Outros autores, como Durham (2004), superam as idílicas ideias sobre as comunidades, como espaços harmoniosos e homogêneos, argumentando a existência de conflitos e paixões característicos dos espaços humanos.

Considerando a estrutura socioprodutiva e as racionalidades que a ela se relacionam na comunidade de Campo Redondo de Itamonte, Minas Gerais, podemos entender, segundo Brandão (2007), a impossibilidade teórica de compreender as comunidades rurais como unidades homogêneas. As múltiplas transformações, no rural brasileiro, as pressões contra a agricultura e modo de vida campesina que exerce o agronegócio, o aumento da porosidade das fronteiras com o mundo urbano e as múltiplas estratégias produtivas que as famílias camponesas desenvolvem permitem a existência de um mosaico diverso de comunidades rurais. Para Brandão (2007, p. 54), considerar a diversidade e polissemia permitiria "compreender algo das experiências de espaço-tempo entre as comunidades diferenciadamente situadas nos diferentes pontos de intervalo entre as culturas e comunidades de pequena socialização de espaços da natureza e de uma economia de consumo...".

Este estudo ocorreu na comunidade rural de Campo Redondo, pertencente à cidade de Itamonte, Sul de Minas Gerais/Brasil na porção mineira da Serra da Mantiqueira, próxima à divisa do estado de São Paulo (Figura 1). A população estimada do município de Itamonte é de 15.579 habitantes e sua área territorial é de $431,792 \mathrm{~km}^{2}$. A densidade demográfica é de 32,43 habitantes por $\mathrm{km}^{2}$ e o Índice de Desenvolvimento Humano Municipal (IDHM) é de 0,705 (IBGE, 2020). A Serra da Mantiqueira contém fragmentos do bioma Mata Atlântica, incluindo formações características com Florestas Ombrófilas, com presença de Araucaria angustifolia, considerada espécie prioritária para a conservação (DTEZEL et al, 2018). 


\section{Figura 1 - Mapa de localização do município de Itamonte em Minas Gerais.}

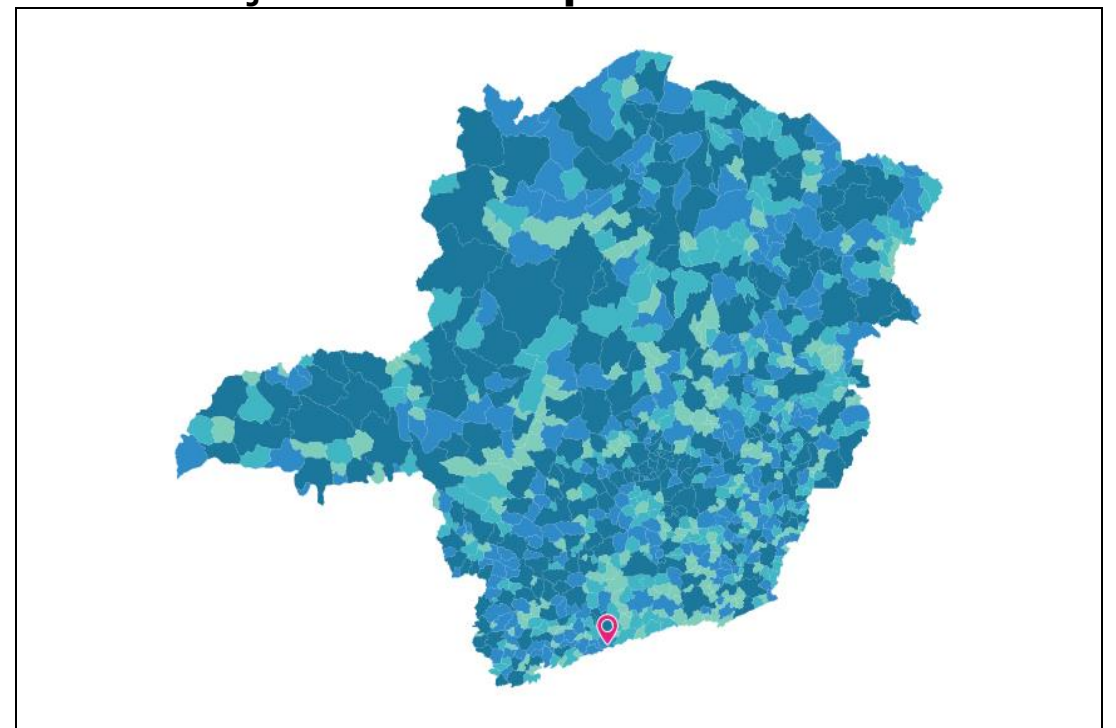

Fonte: IBGE, 2020.

A economia do município é voltada, principalmente, à agropecuária e ao turismo. Observa-se o predomínio da pecuária e criação de outros animais, cuja porcentagem de número de estabelecimentos por predomínio de uso do solo alcança $88 \%$ para essa finalidade, enquanto a lavoura temporária apresenta $4,4 \%$ (ICMBio, 2013). Cabe ressaltar que atividades econômicas pautadas na pecuária, historicamente, têm pressionado a natureza.

A comunidade rural de Campo Redondo está localizada a 1500 metros de altitude, $32 \mathrm{~km}$ de distância do centro de Itamonte, situada entre dois importantes parques: Parque Estadual da Serra do Papagaio e Parque Nacional de Itatiaia. Em virtude de sua relevante localização, em termos de importância ambiental, Campo Redondo faz parte da Área de Preservação da Serra da Mantiqueira (APASM), criada em 1985. A APASM engloba 27 municípios, estendendo-se por 402.508 ha em três estados brasileiros (Rio de Janeiro, São Paulo e Minas Gerais).

\section{Figura 2 - Mapa de localização da comunidade de Campo Redondo, Itamonte/MG}

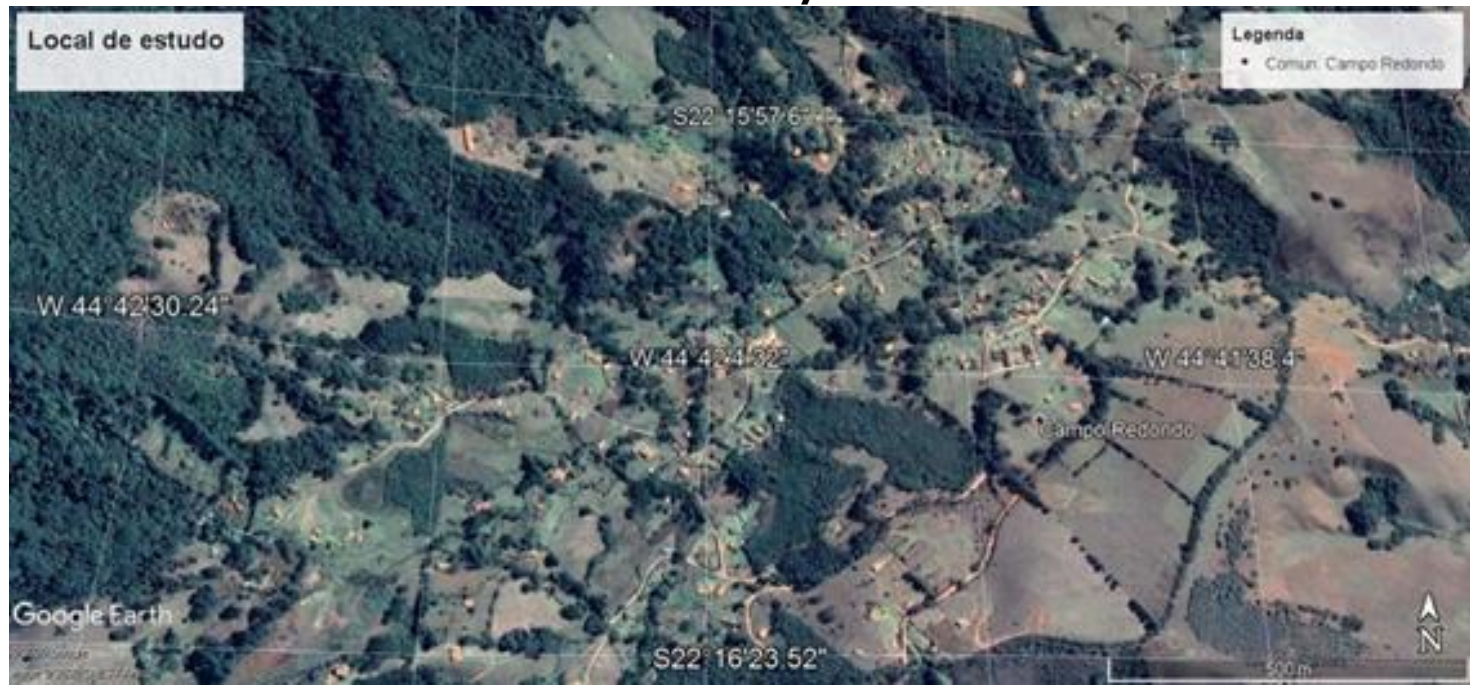

Fonte: Elaboração própria a partir do Google Earth, 2020. 
A comunidade rural contava com 85 famílias cadastradas no posto de saúde e ainda turistas com residência fixa no local, porém não cadastrados. Dentre as atividades econômicas marcantes na comunidade estão: pecuária leiteira, produção de queijo parmesão, criação de truta, produção de cogumelo e apicultura. Das atividades econômicas que geram uma renda complementar estão: geleias caseiras, sucos concentrados, coleta e venda de pinhão, produção de lã. A cultura da "cata" do pinhão representa alternativa de renda complementar importante, para a comunidade rural de Campo Redondo, em termos de qualidade de vida, além de representar um alimento importante à época do inverno atraindo turistas para a região.

A comunidade possui uma escola municipal "Bruno Fonseca Pinto" que fica ao lado da igreja principal e atua com educação infantil e etapas iniciais do ensino fundamental (até o $5^{\circ}$ ano). Possui 76 estudantes e grande parte dos seus professores são moradores da comunidade. A maioria dos moradores cresceram na comunidade e estudaram, em sua escola rural, com a qual possuem vínculos diretos ou indiretos.

A pesquisa segue um enfoque qualitativo e foi norteada, a partir da perspectiva da investigação-ação desenvolvida pela escola, propícia a favorecer mudanças nos espaços socioeducativos e comunitários por seu caráter críticoreflexivo e emancipatório. Segundo Carr e Kemmis (1988), é um processo que vincula, ao mesmo tempo, pesquisa, ação, problematização crítica da realidade, construção teórica e prática.

Para a melhor compreensão da realidade, uma das autoras se mudou para a comunidade de Campo Redondo, durante seis meses, a fim de desenvolver uma pesquisa qualitativa e utilizou, como principais técnicas, entrevistas, observação participante e análise documental. De acordo com Triviños (1987), a pesquisa qualitativa busca compreender como determinados fenômenos manifestam-se a partir da visão dos participantes. A análise documental foi realizada, com base em um livro sobre a história de Campo Redondo, escrito por um grupo de membros da comunidade, em um projeto de pesquisa de escola e, também, com outros documentos, como Plano de Ação do Corredor Ecológico da Mantiqueira e uma cartilha, materiais disponibilizados pelos moradores.

A partir do segundo dia de campo, foram iniciadas entrevistas e observação direta, bem como anotações em diário de campo. Foram realizadas vinte e uma entrevistas semiestruturadas com moradores da comunidade, sendo três entrevistadas professoras da escola. As entrevistas foram gravadas e transcritas, para facilitar a posterior análise e organizadas, em vários temas, dentre eles, o da Educação Ambiental na escola, história da comunidade, dentre outros não enfatizados neste artigo.

A partir do segundo mês na comunidade, foi utilizada a observação participante. À medida que havia aproximação com os moradores da comunidade, houve abertura por parte da direção da escola, para que se observasse seu cotidiano e, num segundo momento, participasse ativamente das ações desenvolvidas pela escola via projeto de Educação Ambiental. A observação participante na escola possibilitou a participação, no cotidiano das atividades do projeto de Educação Ambiental, bem como muitos momentos de diálogo com a diretora, coordenadora, professoras, estudantes e demais servidores da escola e 
com a comunidade, facilitado pelo convívio frequente e pela construção de relações de amizade.

Para alcançar os objetivos, esta pesquisa foi desdobrada em ações de aproximação e sistematização da experiência, desenvolvidas pela escola em que foi possível construir a linha do tempo, desde a problematização da realidade ambiental e o desenvolvimento de um tema gerador pelas docentes da escola até a participação no projeto de Educação Ambiental.

Neste processo, os estudantes assumiram a condição de protagonistas das ações, construindo consciência crítica sobre o tema. Finalmente, a articulação entre o projeto escolar e a comunidade possibilitou a socialização do conhecimento, o pensar as ações pautadas na conservação ambiental, para além da sala de aula, em que as docentes atuaram como facilitadoras.

O uso de entrevistas, da análise documental e da observação participante foi relevante para compreender como se chegou ao aqui situado, numa leitura, a partir da ecoformação e Educação Ambiental. Os métodos utilizados permitiram a compreensão da história que antecede o projeto e seu impacto para as relações entre comunidade e a natureza.

O trabalho de campo prolongado propiciou acompanhar o Projeto de Educação Ambiental: "Preservando as Araucárias" da escola, bem como resgatar seu histórico ao desenvolvimento de projetos de Educação Ambiental, em que a proposta metodológica de Paulo Freire é a chave de cada uma das ações de pesquisa, sensibilização e conscientização, que inclui a construção dialógica do conhecimento, a participação, o reconhecimento de saberes outros numa espécie de ecologia de saberes (SANTOS, 2006). Sendo assim, o uso do teatro interativo, da música e da poesia são ferramentas educativas à sensibilização que acionam a necessidade de conservação das araucárias e a cadeia produtiva a elas relacionada.

Os dados foram analisados, de acordo com a proposta de Minayo (2001), sendo ordenados e classificados, seguida da análise propriamente dita. A sequência de análises indicou o caráter interativo da pesquisa de maneira que as pressuposições, primariamente construídas, passaram por um constante processo de desconstrução e reconstrução referente ao processo de investigação.

\section{Resultados e discussões}

Ao interagir com a escola, inicialmente, pretendeu-se conhecer o histórico de projetos sobre Educação Ambiental relacionados à conservação da Araucaria angustifolia realizados pela escola da comunidade de Campo Redondo. De acordo com funcionários, os projetos tiveram início, na década de oitenta, por meio de iniciativas de plantio de araucária, com a produção de mudas feitas pelos alunos com a ajuda dos professores. Os plantios das mudas ocorreram em propriedades particulares.

À medida que o IBAMA (Instituto Brasileiro do Meio Ambiente e dos Recursos Naturais Renováveis), a fiscalização foi aparecendo, foi mostrando pra gente que isso deveria ser preservado, que devia ser uma árvore proibida de cortar, e muitas pessoas foram multadas porque cortavam, e nós como escola sentimos a necessidade de passar pras crianças que o pinheiro deveria ser plantado e não cortado, aí montamos um projetinho que teve um resultado muito bom, conseguimos fazer as mudas e plantamos em toda beira do 
córrego que corta Campo Redondo, começando lá embaixo. Teve proprietário que não aceitou bem nossa ideia, teve uns que arrancaram as mudas que nos plantamos, então esses pinheiros que você pode ver na beira do córrego foram de gente que aceitou e hoje as pessoas catam pinhão desses pinheiros. (Entrevistada 15, uma das primeiras professoras da escola de Campo Redondo)

Ao longo do tempo, com a realização de projetos na escola com as crianças e também pelos costumes da própria comunidade, observou-se que estava em construção uma relação de pertencimento por parte dos moradores, principalmente as crianças, com pinheiro brasileiro. Isso porque elas vivenciam no seu dia a dia a importância da árvore para gerar lenha, gerar a "palha" para acender o fogo, gerar a primeira renda por meio da "cata" do pinhão, pelas sombras proporcionadas pela árvore, protegendo-as do sol e pela produção de alimento (pinhão).

Durante a observação participante e pelas entrevistas, percebeu-se que, à medida que a questão da conservação dessa espécie foi sendo construída com as crianças, elas tornaram-se sujeitos ativos da construção do conhecimento e se interessaram pelo assunto, já que ele representa parte intrínseca de suas vidas, de sua cultura. Por isso, os projetos trabalhados na escola desde a década de oitenta repercutiram, na opinião dos entrevistados, de maneira positiva, colaborando para a conscientização sobre a importância de se preservar e plantar a araucária. A escola tem o entendimento de que a araucária representa um símbolo à comunidade e todos dependem dessa espécie que se encontra em extinção.

Hoje eu vejo que aquele projeto instigou as pessoas a plantarem, porque muitos anos depois observei que alguns dos meus alunos da época que participaram do projeto hoje fazem mudas, plantam, ensinam seus filhos, teve aluno meu que se tornou produtor de mudas e deu continuidade ao trabalho, então eu vejo que valeu pra eles. (Entrevistada 15, professora)

Como resultado do projeto desenvolvido, na década de oitenta, referente ao plantio de mudas de araucárias pelos alunos, como foi relatado anteriormente, foi possível observar uma linha de plantio de árvores araucárias grandes e vistosas à beira do rio principal que corta a comunidade (Rio Aiuruoca). Desse modo, todo o conhecimento prático que possa contribuir à melhoria da qualidade de vida, bem como ao uso sustentável dos recursos locais, pode ser trabalhado pela escola. Por isso, a escola acredita que incentiva e contribui para a permanência dos jovens no campo.

Eu formei em 2013, e eu sei que desde 2013 de todas as turmas que formaram na escola só uma pessoa foi embora de Campo Redondo, de resto todo mundo vive e trabalha aqui, a maioria do pessoal que formou trabalha hoje com truta principalmente e cogumelo, que são produtos mais novos na comunidade, a truta começou em 2006, mas o cogumelo, por exemplo, a gente começou a mexer tem só três anos. Aí nas mostras culturais a escola trabalha em cima desses temas trazendo muita informação boa pra gente que mexe com essas coisas, nisso a escola contribui muito, e incentiva muito os alunos. (Entrevistado 19, agricultor familiar)

Mais recentemente, os projetos da escola ligados à conservação da espécie são realizados, por meio de pesquisa e troca de informações sobre a espécie, 
receitas com o pinhão, no sentido de valorizar esse alimento na cultura local. 0 acesso à internet é relativamente recente na comunidade, aproximadamente, em 2013. De acordo com relatos, a internet possibilitou maior acesso a informações técnicas que são utilizadas nos projetos atuais da escola.

Segundo relatos de duas professoras do terceiro e quinto ano do ensino fundamental, já foi proposto pela escola um projeto para sensibilizar os alunos para a conservação da araucária, utilizando temas que despertassem a sua curiosidade. Os professores passaram aos alunos os temas específicos (por exemplo: como diferenciar o pinheiro macho do pinheiro fêmea), e os alunos foram orientados a pesquisarem em casa junto com seus pais, perguntando-lhes o que sabiam a respeito do tema. Utilizaram também para a pesquisa informações na internet.

Por meio da interação com os alunos, foi possível observar a sua apropriação do conhecimento, a respeito dos animais no ecossistema natural que se alimentam do pinhão, assim como o uso de boas práticas de coleta do pinhão e formas de diferenciar a araucária macho e fêmea, além de outros aspectos interessantes sobre a espécie.

As professoras relataram que os alunos chegaram a comentar que muitas informações os próprios pais sabiam e trocaram esse conhecimento com eles, outras informações surgiram por pesquisas pela internet, despertando inúmeras curiosidades nos alunos e em seus pais e, ainda, pela troca de informações em sala, de modo que todo o conhecimento gerado naquele processo foi compartilhado entre pais, alunos e professoras.

Antes meu filho queria deixar as mudas crescendo debaixo do pinheiro. Aí eu perguntei a ele: Como você acha que o pinheiro vai crescer debaixo da pinheira? Aí ele fala assim: "Ih é mesmo mãe, aí depois a pinheira não vai dar espaço pra esse crescer pra cima! Ele aprendeu pela escola também, ano passado teve um projeto com pinhão, porque as pessoas estavam só trepando em cima das pinheiras e derrubando as pinhas, maltratando os pinheiros e nessa corrida, porque o preço tava bom então teve muita briga, aí teve esse projeto pra conscientizar o povo. Depois desse projeto percebi que diminuiu muito essa mania do povo de derriçar os pinheiros. Aí esse ano vai ter continuação, mas com culinária de pinhão. Ano passado foi de cuidar do pinheiro e plantar. (Entrevistada 6, mãe de dois alunos da escola e agricultora familiar)

Ao longo deste trabalho, as atividades do projeto de Educação Ambiental ganharam maiores proporções e foram reconhecidas pela escola como fundamental para serem expostas na "Mostra Cultural" da comunidade de Campo Redondo. A Mostra Cultural organizada pela escola é realizada na comunidade de Campo Redondo anualmente. O objetivo principal é elaborar com os alunos uma peça de teatro e expor os trabalhos realizados por eles de acordo com as demandas da própria comunidade. Como exemplo, podem-se citar os trabalhos de conservação da araucária, preservação das nascentes da região, construção de filtros rústicos para evitar a poluição das águas pela criação de truta, dentre outros temas, que exploram as questões ecológicas e sociais da comunidade.

Na mostra cultural, nós tentamos dialogar com a comunidade, por exemplo, a gente pega um assunto que diz respeito a comunidade e trabalha em forma de teatro. Ano passado eles trabalharam a questão da terra mesmo, a importância da água, como a gente viveu esses três a quatro anos de seca 
braba, foi trabalhado a importância da água e de economizar, mesmo morando no meio rural e em forma de teatro, aí o povo gosta, vai lá e assiste, e assim essa conscientização é socializada. (Entrevistada 9, professora da escola)

Foi proposto aos alunos que apresentassem um teatro para a comunidade sobre preservação das araucárias, considerando que o teatro é uma das apresentações mais apreciadas e prestigiadas pela comunidade. O roteiro do teatro foi elaborado e discutido em conjunto com o objetivo de abordar a conscientização sobre os métodos de coleta. O intuito foi mostrar que não há necessidade de forçar a caída dos pinhões, já que eles caem naturalmente, mostrando o quão prejudicial para a manutenção da espécie são as práticas de coleta tradicionais, como subir no pinheiro para "derriçar", ou seja, chacoalhar e derrubar as pinhas. Foi abordada, também, a importância que a araucária possui em vários aspectos para a comunidade. A peça foi concebida de maneira interativa e com linguagem simples, garantindo o entendimento das informações trabalhadas a toda a comunidade.

Além da apresentação teatral, houve também grupos que apresentaram curiosidades sobre a araucária, assim como poemas e músicas feitos pelos alunos sobre a importância de preservar esta espécie. Essas atividades possibilitaram que grande parte da comunidade tivesse acesso aos trabalhos.

Um relato interessante a ser ressaltado se refere a uma conversa que aconteceu com um aluno na escola que discorreu sobre a importância da gralha azul, como sendo a principal espécie animal que se alimenta do pinhão e sua importância na dispersão da espécie. A partir dessa informação, foi identificada uma falta de informação sobre a relação da araucária com a fauna nativa, pois muitas informações e trabalhos disponíveis na internet dizem respeito às dinâmicas de vegetação e fauna ao Sul do país e não de sua própria região. Isso foi verificado, no decorrer da pesquisa, já que praticamente todo o material que reúne informações sobre araucária abordam a realidade da região Sul do Brasil, não sendo encontradas informações sobre a dinâmica populacional de araucárias da Serra da Mantiqueira.

\footnotetext{
Quando teve esse projeto de pesquisa sobre a araucária, eu descobri que nessa região nós temos a gralha branca, que se alimenta do pinhão, assim como a gralha azul no sul do Brasil, acontece que ninguém sabe sobre isso, todo mundo sabe sobre a gralha azul que nem faz parte na nossa realidade, então é o que eu falo, a gente tem acesso a internet e a várias informações, mesmo assim pouco sabemos sobre a nossa própria região. As dinâmicas aqui com relação a araucária e muitas outras espécies são únicas, diferentes de outras regiões, e como nós vamos valorizar isso se não temos os meios pra isso? (Entrevistada 18, professora)
}

Esse fato remete à necessidade da construção do conhecimento junto com comunidades rurais da Serra da Mantiqueira, bem como a confecção e disseminação de materiais que tratem sobre a conservação da araucária, a partir da cultura, dinâmica ambiental e realidade local.

Após conhecer este histórico relacionado ao projeto de Educação Ambiental e pelo fato de uma das pesquisadoras estar residindo na comunidade e convivendo com a realidade local da escola e da comunidade, ao longo do tempo, surgiu o convite da escola, para participar de forma ativa em seu projeto relacionado à 
preservação da araucária intitulado "Projeto de Educação Ambiental: preservando as araucárias". Neste projeto, pôde-se acompanhar, compreender e vivenciar todo o processo educativo, pedagógico, social e ambiental trabalhado pela escola e de que maneira tais iniciativas educacionais repercutem na construção do conhecimento da comunidade. Assim, observou-se, positivamente, o envolvimento e empolgação dos alunos quanto aos projetos ambientais.

Por essa razão, o potencial dessas atividades educativas é significativo, no entanto devem ser constantemente aprimorados, para que se adequem cada vez mais às necessidades e aos anseios dos alunos e da comunidade. Para que isso ocorra, é fundamental um processo de avaliação dos projetos que já foram desenvolvidos visando melhorar os novos projetos a serem implementados na área de Educação Ambiental. Além disso, observou-se a necessidade de aporte financeiro, para viabilizar novos projetos de Educação Ambiental na escola, assim como a confecção de materiais didáticos que poderiam ser distribuídos pela rede municipal de escolas rurais da região, contribuindo para a disseminação da cultura, saber local e práticas sustentáveis.

Quando tem aula de campo é uma festa! Saímos da sala de aula, coisa que não era comum naquela época, ficamos um bom período escolhendo as sementes, preparando as mudas, muitas delas nós fizemos no saquinho pra depois ir pro chão, muitas nos plantamos direto no chão, pra depois perceber a diferença entre as diferentes formas de plantar, os alunos adoraram esses momentos e aprenderam muito também. Hoje as aulas de campo são mais constantes, os alunos são instigados a pesquisarem e buscar conhecimento do nosso passado com os mais velhos. (Entrevistada 15, professora)

Tanto as aulas de campo quanto as outras atividades de interação da escola com a comunidade, como as "Mostras Culturais", criam espaços de aprendizagem úteis e práticos à realidade rural. Essas formas de atividades educacionais possuem um potencial a ser trabalhado com os alunos. Esses espaços propiciam oportunidades, ao estimular atividades que podem ser desenvolvidas por eles em suas terras, com o objetivo tanto de gerar renda, como melhorar a qualidade ambiental.

Durante a observação participante, em diálogo com as professoras e com a escola, foram elaboradas saídas a campo como parte do projeto de Educação Ambiental que estava sendo desenvolvido. Este projeto visou sensibilizar os alunos, para a conservação da araucária, por meio de pesquisas sobre curiosidades da espécie. Esta metodologia possibilitou maior participação dos alunos, que puderam absorver de maneira mais crítica o conhecimento construído por eles juntamente com os pais e professores. Segundo o relato de três mães, por meio de conversas informais, muitas curiosidades sobre a araucária elas não sabiam até pesquisarem com seus filhos e junto com eles descobriram muita coisa interessante sobre a espécie.

O projeto "Preservando as Araucárias" estava com foco nas receitas feitas, a partir do pinhão, com o objetivo de valorizá-lo enquanto alimento, explorando sua potencialidade, a partir de diversas receitas e, desta forma, aumentar as possibilidades de seu uso na própria comunidade. Visou também sensibilizar a comunidade, para a importância da preservação da araucária, a fim de que essa 
árvore não desapareça e possa beneficiar a comunidade e a manutenção do ecossistema local.

O projeto organizou espaços de confecção de receitas culinárias relacionadas ao pinhão. A princípio, as crianças ficaram responsáveis por levarem receitas com pinhão, que fazem em casa, para que fossem, posteriormente confeccionadas, na própria escola. Logo depois, foi escolhida e preparada uma receita por turma para que todos pudessem comer no momento da merenda. Um aspecto relevante do projeto foi a participação das crianças que ficaram responsáveis por picar todos os ingredientes e, principalmente, descascar o pinhão. Foi observado que cada criança tinha sua própria técnica para descascá-lo.

As professoras orientaram os alunos sobre as quantidades certas dos ingredientes a serem colocados nas panelas ou liquidificador e explicavam cada etapa do processo, de modo que todas as crianças participassem de cada uma das etapas. As crianças se dedicaram à atividade e participaram a todo momento, sentiram-se parte daquele processo e orgulhosas com os resultados finais. Por fim, todos se deliciaram com as receitas que, ao fim do projeto, foram reunidas, em um livro de receitas, ofertado para a família de cada criança que participou do projeto.

Os livros de receitas foram impressos e oferecidos como presente da escola a cada família no "dia da família". Foi preparada uma atividade na escola com as crianças e seus familiares, em que todas as famílias levaram pratos feitos com o pinhão e puderam contemplar as fotos do projeto realizado com as crianças. Cabe ressaltar que as famílias dos estudantes possuem o hábito de enviar com frequência alimentos de suas propriedades (como ovos, pinhão, temperos, hortaliças, etc) para complementar e enriquecer a alimentação ofertada pela escola. Desta forma, o dia da família foi também mais uma oportunidade de as famílias contribuírem com a alimentação da escola, bem como uma oportunidade de valorização de saberes e integração entre escola, comunidade e araucária.

Dentro do projeto, também, foram organizadas atividades relacionadas à produção de mudas de araucária. A orientadora do projeto seguiu um protocolo de germinação de pinhão. O espaço foi iniciado com uma saída de campo pela estrada da Fragária (local mais próximo da escola onde há uma fileira extensa de araucárias) para que as crianças coletassem apenas três sementes cada. Em seguida, a coordenadora sentou-se com os alunos ao ar livre para explicar o procedimento de plantio e discutir sobre alguns aspectos da semente, da germinação, problematizando os processos de plantio, bem como compartilhando conhecimentos que os alunos possuíam.

Logo depois, as crianças foram levadas até uma bica onde elas puderam lavar as sementes com água corrente e, após, deixaram as sementes espalhadas em um pedaço de papelão em local arejado. A última etapa foi plantar as sementes dentro de garrafas pet, propriamente cortadas pelas professoras, com substrato coletado próximo à escola, cuja composição era: areia, folhas e flores. Essa parte do projeto contou com a intensa participação dos alunos, assim como a dedicação da orientadora ao pensar em todos os passos e procedimentos para a produção das mudas.

A partir da participação neste espaço, pode-se fazer algumas sugestões visando agregar a futuros projetos. Foi sugerido explicar e discutir sobre o crescimento da semente, o porquê de cada passo do protocolo. Outro aspecto observado foi que as crianças não entenderam sobre a quantidade de água 
necessária, sendo uma oportunidade para ensinar alguma proporção, para que as crianças tivessem uma noção básica de dosar a quantidade de água ao cultivo de mudas de maneira geral.

Dentre as sementes coletadas, algumas estavam velhas, secas, pequenas, ou seja, não foi trabalhada a seleção das melhores sementes, fator fundamental para a confecção de mudas; essa parte seria muito importante para que elas próprias separassem e escolhessem suas sementes. Outro fator é que apenas $40 \%$ das sementes germinam. Como os alunos plantaram somente três cada um, possivelmente, muitos podem não conseguir obter uma muda e acompanhar seu crescimento. Por isso, seria interessante germinar um maior número de sementes para que até o fim do projeto eles pudessem formar mudas.

Uma ideia que surgiu, a partir das experiências, foi a construção de um protocolo de germinação da semente de araucária que seria construído pelos próprios alunos por meio de pesquisas e sob orientação. No entanto, como já existem pessoas na comunidade que produzem mudas de araucária e possuem conhecimento do processo, poderiam ser consultados e visitados pelos alunos.

De maneira geral, observou-se que o projeto de Educação Ambiental e o ambiente escolar promoveram um fértil espaço de curiosidade, pertencimento, valorização e integração dos saberes entre os estudantes/escola/comunidade o que reforça a importância da continuidade de projetos como esse.

[...] hoje em dia ninguém quer ir embora (da comunidade). Acho que isso mudou por causa dos trabalhos na escola que valorizou a cultura no campo, trouxe perspectivas pra várias atividades. Antes os professores vinham tudo de fora, hoje quase todos os docentes formaram aqui. A escola é fundamental aqui. Costuma ter a semana de Arte cultural, que aborda vários temas, araucária mesmo, nascentes d'água, lixo, reciclagem, ai a turma da escola pesquisa elabora um trabalho que é apresentado pra comunidade, por isso eu falo que hoje conscientizou muito a população referente a derrubada de árvores. (Entrevistado 1, jovem de 21 anos morador da comunidade)

Com base nesses resultados, pode-se evidenciar a proposta de ecoformação, no contexto deste estudo, à medida que se observa a reconstrução das relações entre escola, comunidade e as araucárias percebidas no cotidiano e perpassando os vários aspectos da vida.

Salienta-se também o papel importante de se resgatar e dar visibilidade a iniciativas e projetos das escolas como este, via pesquisa qualitativa, que possibilitam maior compreensão de uma realidade. Um dos moradores da comunidade que acompanhou de perto o desenvolvimento desta pesquisa qualitativa manifestou satisfação em participar desta experiência e abertura para novos processos de pesquisa. Ele, inclusive, estava presente e assistiu à defesa do TCC na universidade, compartilhando essa experiência com outros moradores posteriormente. Foram também disponibilizadas cópias impressas do trabalho que fazem parte do acervo da biblioteca, sendo lido por membros da comunidade, como, por exemplo, a coordenadora da escola que manifestou satisfação com o que estava escrito e pelo fato de estar disponível na biblioteca, fazendo parte de seus registros, resgatando e valorizando um pouco da história da escola, comunidade e sua relação com a Araucária angustifolia. 


\section{Considerações finais}

Refletir sobre as experiências ecoformativas, como as favorecidas pelas ações do Projeto de Educação Ambiental: "Preservando as Araucárias", desenvolvido pela Escola Municipal Bruno Fonseca Pinto, mostra outras maneiras que nos ensinam novos caminhos, para construir conhecimento ambiental, por meio do desenvolvimento de práticas educativas, em diálogo com seu contexto local e do estabelecimento de uma relação sustentável e cuidadosa com a natureza.

Para a comunidade de Campo Redondo, a conservação da espécie em si está diretamente aliada à preservação cultural local, em seu abrangente leque de relações construídas entre o seu povo e a araucária, ao longo de gerações, passadas sempre adiante. Por isso, no momento em que a escola passa a trabalhar essa correlação, a consequência é a integração de inúmeros aspectos de ordem ecológica, histórica, cultural e econômica, a conservação da espécie, a valorização e socialização da história, valorização da cultura local e incentivo por uma economia sustentável. Essa integração evidencia as múltiplas inter-relações intracomunidade entre a comunidade e a escola e entre escola, natureza e comunidade.

A fertilidade da proposta está em fortalecer o espaço escolar e a integração entre a comunidade e as araucárias, como protagonistas de um processo que, aos poucos, vai germinando relações de inter e ecodependencia. As ações desenvolvidas mobilizaram a consciência sobre as araucárias, como parte da reprodução da vida e da cultura, transcendendo a ideia de objeto apropriado e mercantilizado.

Dessa forma, entende-se que o Projeto de Educação Ambiental "Preservando as Araucárias", desenvolvido na escola, gerou cenários interativos e dialógicos que permitiram a valorização da espécie no contexto ecológico, histórico, cultural e econômico, e a pesquisa sobre receitas com o pinhão trabalhou a valorização do pinhão como um alimento único, diverso em suas maneiras de preparo. Além disso, incentivou o diálogo entre as famílias e inspirou os alunos a quererem plantar mais árvores, questionarem o porquê suas famílias não o fazem e aprenderem a cozinhar pratos com o pinhão.

O projeto gerou também um material muito valioso, que é o acervo de receitas com pinhão, receitas criadas pelas mulheres, passadas por gerações, utilizadas nos festivais culturais que contribuem, anualmente, para a valorização da cultura local e arrecadação de verba para projetos de desenvolvimento da própria comunidade.

O trabalho desenvolvido pela escola, por meio do projeto, possibilitou encarar um problema ambiental situado no contexto comunitário. Problematizar sobre os riscos da extinção das araucárias e propor ações colaborativas, a partir do princípio da precaução, mostram que as araucárias são mais que paisagem, fazem parte de sua história, da biodiversidade e da experiência vital da comunidade e da escola.

As comunidades rurais articuladas à escola rural constituem uma peça fundamental para contribuir à conservação dos remanescentes das florestas de araucária e a biodiversidade a elas relacionada. No entanto observa-se importância de aproveitar essa potencialidade, para desenvolver mais projetos, pesquisas, porém investindo na confecção de materiais educativos ou outros produtos técnicos. Propostas assim contribuem com uma relação mais harmônica com a 
natureza e com a formação de sujeitos conscientes e transformadores da própria realidade.

Portanto percebe-se a necessidade de haver a continuidade de trabalhos desta natureza que visem estimular a produção de mudas, o plantio e valorização cultural da Araucaria angustifolia. É importante que as novas gerações do campo compreendam e valorizem a araucária, como símbolo da sua cultura, como importante fonte de recurso sustentável gerador de renda, bem como suas potencialidades para agregar valor.

\section{REFERÊNCIAS}

AMARAL, Marcelo Mendes do; FICHINO, Betânia Santos. Construção participativa de diretrizes para o manejo sustentável do pinhão (Araucaria angustifolia) a partir de uma visão da conservação da floresta com araucária e do uso do pinhão. Conselho Nacional da Reserva da Biosfera da Mata Atlântica, Caderno n. 43, 2014. Disponível em: http:// www.rbma.org.br/rbma/pdf/caderno_43.pdf Acesso em: 25 jun. 2020.

BRANDÃO, Carlos Rodrigues. Plantar, colher, comer: um estudo sobre o campesinato goiano. Rio de Janeiro: Edições Graal, 1981.

BRANDÃO, Carlos Rodrigues. Tempos e espaços nos mundos rurais do Brasil. Revista Ruris, v. 1, n. 1, p. 37-64, 2007.

BRASIL. Plano Nacional de Promoção das Cadeias de Produtos da Sociobiodiversidade. 2009. BRASÍLIA: MDA/MMA/MDS. Disponível em: http://bibliotecadigital.seplan. planejamento.gov.br/bitstream/handle/123456789/1 024/Plano\%20Sociobiodiversidade.pdf?sequence=1\&isAllowed=y Acesso em: 10 fev. 2016.

BRASIL. Ministério do Meio Ambiente. Bioma Mata Atlântica. 2008. Disponível em: http:// www.mma.gov.br/biomas/mata-atlantica. Acesso em: 28 jun. 2016.

CARVALHO, Isabel Cristina de Moura. Educação ambiental: a formação do sujeito ecológico. 6. ed. São Paulo: Cortez, 2008.

CARR, Wilfred; KEMMIS, Stephen. Teoría crítica de la enseñanza: la investigación-acción en la formación del profesorado. Tradução de J. A. Bravo. Barcelona: Martinez Roca, 1988.

CERTI - Centro de Referência em Tecnologias Inovadoras. Diagnóstico das Cadeias Produtivas do Pinhão e da Erva-Mate. In: CERTI - Centro de Referência em Tecnologias Inovadoras. Análise Integrada das Cadeias Produtivas de Espécies Nativas da Floresta Ombrófila Mista e seu impacto sobre este Ecossistema. Fundação Grupo Boticário, v. 1, fev. 2012. 
DANNER, Moeses Andrigo; ZANETTE, Flávio; RIBEIRO, Juliana Zanetti. O cultivo da araucária para produção de pinhões como ferramenta para a conservação.

Pesquisa Florestal Brasileira. v. 32, n. 72, p. 441-451, 2012.

DETZEL, Valmir Augusto; BALDIM, Matheus Morganti; CIT, Cristiano; LAMBERTI, Sandy Plassmann. Instituto Chico Mendes de Conservação da Biodiversidade. Plano de manejo da Área de Proteção Ambiental da Serra da Mantiqueira. Detzel Consultores Associados S/S EPP. Brasília, 2018. p. 371.

DURHAM, Eunice Ribeiro. Comunidade. In: Omar Ribeiro Thomaz. A dinâmica da cultura: ensaios de antropologia. São Paulo: Cosac Naify, 2004. p. 221-225.

DURKHEIM, Emile. La división del trabajo social. Akal, Madrid, 1987.

FICHTER, Joseph H. Richter. Definições para o uso didático. In: FERNANDES, Florestan. (Org.). Comunidade e sociedade: leituras sobre problemas conceituais, metodológicos e de aplicação. São Paulo: Editora da Universidade de São Paulo, 1973. p. 153-155.

FLORIANI, Guilherme dos Santos Freire. Debulhando pinha, semeando pinhão: propostas de uso e conservação para a araucária. Rev. Bras. Agroecologia, v. 2, n. 1, fev. 2007.

FREIRE, Paulo. Conscientização. São Paulo: Moraes, 1980.

FREIRE. Paulo. Extensão ou Comunicação? 10a ed. Rio de Janeiro: Paz e Terra, 1992.

FREIRE, Paulo. Educação como Prática da Liberdade. 17a ed. Rio de Janeiro: Paz e Terra, 1983.

IBGE - Instituto Brasileiro de Geografia e Estatística. Panorama. Rio de Janeiro: IBGE. 2020. Disponível em:

https://cidades.ibge.gov.br/brasil/mg/itamonte/panorama Acesso em: 20 jan. 2020.

ICMBio - Instituto Chico Mendes de Conservação da biodiversidade. Diagnóstico socioeconômico, histórico e cultural da área de proteção ambiental da Serra da Mantiqueira. Diretoria de Planejamento, administração e logística, Curitiba-PR, 2013.

LEFF, Enrique. Complexidade, Racionalidade Ambiental e Diálogos de Saberes. Educação e Realidade. v. 34, n. 3, p. 17-24, set/dez, 2009.

MACIVER, Robert Morrison; PAGE, Charles H.; Comunidade e sociedade como níveis de organização da vida social. In: FERNANDES, F. (Org.). Comunidade e sociedade: leituras sobre problemas conceituais, metodológicos e de aplicação. São Paulo: Editora da Universidade de São Paulo, 1973. p. 117-131. 
NAVARRA, Joan Mallart. Ecoformación, más allá de la educación ambiental. In: De La TORRE, S. Transdisciplinariedad y Ecoformación. Madrid: Universitas, 2007. p. 149-166.

MINAYO, Maria Cecilia de Souza. Ciência, Técnica e Arte: O desafio da pesquisa social. In: MINAYO, Maria Cecília de Souza (org.). Pesquisa Social. Teoria, método e criatividade. $18^{a}$ ed. Petrópolis: Vozes, 2001. p. 9-30.

MORAES, Maria Cândida. Ecopedagogía, Ecoformacao e Consciencia planetária. In: GONZÁLEZ VELASCO J. M. (Org.). Experiências Educativas: Saberes, Ecoformación, Complejidad y Transdisciplinariedad. Impreso en Beltran Impresiones \& Estrategias. La Paz: Bolivia. 1ª Edición, 2019. p. 67-95.

MORIN, Edgar. Os sete saberes necessários à educação do futuro. 2. ed. São Paulo: Cortez, 2011.

SANTOS, Boaventura de Sousa. La Sociología de las Ausencias y la Sociología de las Emergencias: para una ecología de saberes. In: SANTOS, B. de S. Renovar la teoría crítica y reinventar la emancipación social. Buenos Aires: Clacso, 2006. p. $13-41$.

SAUVÉ, Lucie. Educação Ambiental: possibilidades e limitações. Revista Educação e Pesquisa, São Paulo: v. 31, n. 2, maio/ago, 2005. p. 317-322.

SEGURA, Denise S. Baena. Educação ambiental nos projetos transversais. In: Vamos cuidar do Brasil: conceitos e práticas em educação ambiental na escola. Ministério da Educação, Coordenação Geral de Educação Ambiental. Brasília: Ministério do Meio Ambiente, Departamento de Educação Ambiental: UNESCO, 2007.

SILVA, Ana Tereza Reis da. Ecoformação: reflexões para uma pedagogia ambiental. Desenvolvimento e Meio ambiente, n. 18, p. 95-104, jul/dez, 2008.

TEIXEIRA, Antônio Carlos. Educação ambiental: caminho para a sustentabilidade. Revista Brasileira de Educação Ambiental, Brasília: Rede Brasileira de Educação Ambiental, n. 2, p. 21-30, fev. 2007.

TOLEDO, Vitor Manuel. ¿De qué hablamos cuando hablamos de sustentabilidad? Una propuesta ecológico política. Interdisciplina, v. 3, n. 7, p. 35-55, 2015.

TÖNNIES, Ferdinand. Comunidad e sociedad. Tradução José Rovira Armengol. Buenos Aires: Losada, 1947.

TRIVIÑOS, Augusto Nibaldo Silva. Introdução a Pesquisa em Ciências Sociais. São Paulo: Atlas, 1987. 
WIRTH, Louis. Delineamento e problemas de comunidade. In: FERNANDES, Florestan. (Org.). Comunidade e sociedade: leituras sobre problemas conceituais, metodológicos e de aplicação. São Paulo: Editora da Universidade de São Paulo, 1973, p. 83-95.

Recebido em: 15 de julho de 2020. Aceito em: 24 de novembro de 2020. Publicado em: 05 de janeiro de 2021. 